\title{
A critical examination of the idea of evidence-based policymaking
}

\author{
KARI PAHLMAN
}

\section{Abstract}

Since the election of the Labour Government in the United Kingdom in the 1990s on the platform of 'what matters is what works', the notion that policy should be evidence-based has gained significant popularity. While in theory, no one would suggest that policy should be based on anything other than robust evidence, this paper critically examines this concept of evidence-based policymaking, exploring the various complexities within it. Specifically, it questions the political nature of policymaking, the idea of what actually counts as evidence, and highlights the way that evidence can be selectively framed to promote a particular agenda. This paper examines evidence-based policy within the realm of Indigenous policymaking in Australia. It concludes that the practice of evidence-based policymaking is not necessarily a guarantee of more robust, effective or successful policy, highlighting implications for future policymaking.

Since the 1990s, there has been increasing concern for policymaking to be based on evidence, rather than political ideology or 'program inertia' (Nutley et al. 2009, pp. 1, 4; Cherney \& Head 2010, p. 510; Lin \& Gibson 2003, p. xvii; Kavanagh et al. 2003, p. 70). Evolving from the practice of evidence-based medicine, evidence-based policymaking has recently gained significant popularity, particularly in the social services sectors (Lin \& Gibson 2003, p. xvii; Marston \& Watts 2003, p. 147; Nutley et al. 2009, p. 4). It has been said that nowadays, 'evidence is as necessary to political conviction as it is to criminal conviction' (Solesbury 2001, p. 4). This paper will critically examine the idea of evidence-based policymaking, concluding that while research and evidence should necessarily be a part of the policymaking process and can be an important component to ensuring policy success, there are nevertheless significant complexities. It will first consider what evidence-based policymaking is before highlighting its advantages. It will then discuss the issues inherent in the concept, focusing on the political nature of policymaking, the question of what counts as reliable evidence and whose evidence it is, as well as the capacity for evidence to be misrepresented though selective framing 
(McConnell 2010, p. 129). It will use the example of Indigenous policymaking in Australia to highlight some of the major issues. It will be demonstrated that evidence-based policymaking poses significant challenges to policy success.

Evidence-based policymaking, although considered so self-explanatory that it is often not defined in the literature, can be broadly understood as a process that uses rigorous and objective evidence to inform policy development, implementation and practice (Marston \& Watts 2003, p. 144; Nutley et al. 2009, p. 5; AGPC 2009, p. 3). The concept is underpinned by three main characteristics: namely, that evidence should be rigorously tested and capable of replication; that evidence should be robust and methodologically sound; and that the process should be transparent (AGPC 2009, p. 3). The concept gained popularity with the election of the Blair Government in the United Kingdom in 1999 on the platform of 'what matters is what works' (Banks 2009, p. 3; Nutley et al. 2009, p. 4; Sanderson 2002, p. 3; Nutley 2003, p. 2). The Blair Government has been characterised as pragmatic and anti-ideological, as they spoke of questioning 'inherited ways of doing things' (Blair \& Cunningham 2009, p. 16; Solesbury 2001, p. 6; Nutley 2003, p. 3). They asserted the need to develop policies in respect to the evidence rather than as short-term responses to political pressures, and to end ideologically driven decision-making (Blair \& Cunningham 2009, p. 15; Banks 2009, p. 3).

The rise of evidence-based policymaking has also coincided with a decline in confidence in professionals, and an ever-increasingly educated and questioning public (Nutley et al. 2009, p. 4; Solesbury 2001, p. 6). It has been argued that the evidence-based policy agenda marks a decline from the 'priesthood', which had traditionally characterised the operation of professionals 'reliant on the unquestioning faith of their followers' (Pawson 2006, p. 3; Solesbury 2001 , p. 6). People are now less inclined to accept professional practice and power on trust (Solesbury 2001, p. 6). Rather, professionals must be able to explain the appropriateness and efficacy of their advice, with particular focus on cost-benefit and efficiency (Solesbury 2001, p. 6; Marston \& Watts 2003, p. 148). This growing emphasis on evidence-based policymaking has also been seen as part of a greater modernisation agenda of 'progress informed by reason' (Sanderson 2002, p. 1; Cherney \& Head 2010, p. 510). It can be understood as an attempt to professionalise and reform service delivery and practice, with policymaking an exercise in 'systematic problem-solving underpinned by data, risk analysis and the identification of "what works"' (Cherney \& Head 2010, p. 510; Marston \& Watts 2003, p. 145). Essentially, evidence-based policymaking is argued to be a way of modernising policymaking, approaching social issues with rationality in an apolitical and scientised manner (Marston \& Watts 2003, p. 145; Pawson 2006, p. 6; Anderson 2003, p. 226). 
One of the main arguments advanced by proponents of the evidence-based policy agenda is that evidence is important to 'modernise and depoliticise' policymaking in the way that it filters out decision-making bias (McConnell 2010, p. 128). Policies that intervene in the lives of people must be informed by transparent, up-to-date and rigorous research (Hammersley 2005, p. 86). Specifically, policy should not be driven by ideology, but rather objective evidence of what works (Banks 2009, p. 4; Parsons 2002, p. 45; Jensen 2013, p. 3). Without evidence, policymakers can only rely on political ideology, intuition, prejudice, or theory alone, at best (Banks 2009, p. 4). Such resulting policies, despite good intentions, have greater potential to go wrong and lead to costly mistakes, also falling prey to the 'law of unintended consequences' (Banks 2009, p. 5). Essentially, evidence is an important counterweight to neutralise the political energy and vested interests from which policies often emerge (Banks 2009, p. 5, 7). Therefore, evidence is seen as a persuasive mechanism to overcome political ideology and special interest influence, and ensure the policy debate is robust and well informed (Banks 2009, p. 7; Sanderson 2002, p. 3; Nutley et al. 2009, p. 11).

The argument then follows that evidence is necessary to ensuring policy success (McConnell 2010, p. 128). Evidence can not only aid understanding of the likely effectiveness of policies in terms of what works in what circumstances, but it can also inform decisions about how to improve policies through evaluation processes (Sanderson 2002, p. 4). Advocates suggest that research is critical to understanding the intended and unintended effects and impacts of policies and programs (Hammersley 2005, p. 87). It is further argued that the validity of recommendations and policy options underpinned by research is likely to be much greater than those informed by professional experience (Hammersley 2005, p. 89). Moreover, evidence of program outcomes can also be used as a measure of programmatic success, or indeed failure (Marsh \& McConnell 2010, p. 573). That is, evidence of program outputs and outcomes, such as that found in evaluations and audit reports, for example, is often cited by politicians and policymakers alike to demonstrate the success of policies and programs (Marsh \& McConnell 2010, pp. 571, 573).

At face value, it is not hard to understand why the idea that policy should be evidence-based has gained such strength (Hammersley 2005, p. 86). In fact, it would be difficult to imagine anyone suggesting that policy should be based on anything other than good evidence (Marston \& Watts 2003, p. 144). However, the notion of evidence-based policymaking is extremely problematic in several ways and has drawn a significant amount of criticism. One of the major issues that advocates of the concept fail to acknowledge is that policymaking in and of itself is an inherently political process (Marston \& Watts 2003, p. 145; Lewis 2003, p. 250; Nutley et al. 2009, p. 20). It would be foolish to assume that 
research evidence can offer completely objective solutions to political problems such as those concerning education, social welfare or criminal justice (Nutley et al. 2009, pp. 4, 7; Nutley 2003, p. 3). Furthermore, critics of evidence-based policymaking have argued that evidence and evaluation itself is political in the way it is articulated, as all knowledge is socially constructed and contingent (Pawson 2006, p. 6; Taylor \& Balloch 2005, p. 1). Policymaking will never be apolitical or conflict-free, and although certainly helpful for informing the judgements of policymakers, scientific research cannot negate its political nature (Anderson 2003, p. 235; Banks 2009, p. 4).

What counts as evidence is also a concern. The evidence considered to inform evidence-based policymaking is that which has been produced through applied, often academic research (Head 2008, p. 4; Solesbury 2001, p. 8). It is argued that what counts is what has been produced through quantitative methodology and has been tested and validated (Sanderson 2002, p. 6). That is, what can be 'counted, measured, managed, codified and systemized' (Parsons 2002, p. 57). However, the evidence-based policymaking agenda gives little recognition to the multiple evidence bases and forms of knowledge that are necessary to understanding the problems in question, and the prospects of successful intervention (Head 2008, p. 1; Nutley 2003, p. 3). For example, lay knowledge has traditionally been considered as a less important form of evidence, often dismissed as subjective or anecdotal (Maddison 2012, p. 271; Anderson 2003, p. 228; Marston \& Watts 2003, p. 145). However, for many complex issues in the social sphere, technical approaches and systematic research methodologies are inadequate (Head 2008, p. 4). There instead needs to be a greater value placed on stakeholder perspectives and social relations, and evidence gathered through community engagement, including consultations and public inquiries (Head 2008, p. 4; Maddison 2012, pp. 271, 274).

Following this, it should also be noted that not all evidence in the policy process is equal, but that there is a 'hierarchy of knowledge' (Marston \& Watts 2003, p. 145; Maddison 2012, p. 271). The types of evidence that are used and valued in the process represent important power dynamics in policymaking (Maddison 2012 , p. 273). Often, they support the dominant and prevailing ways of thinking about the world, rarely challenging the distribution of power in contemporary society (Stevens 2011, p. 250; Maddison 2012, p. 275). This can be explained in the way the powerful are much better positioned to influence the production and dissemination of research (Maddison 2012, p. 272). As Alex Stevens (2007) notes, marginalised groups, as well as non-elites in the policymaking field:

... have less access to the sources of research and its dissemination; they are less able to impose their interpretations of research evidence on a wider public ... or to impose strain on those who produce or disseminate unhelpful research ... [and] they have less of a role in framing policy (p. 29). 
Such a hierarchy of knowledge demonstrates that evidence-based policymaking is far from neutral (Marston \& Watts 2003, p. 145). Rather, it is extremely valueladen in the way that some forms of evidence are considered more valid than others, reflecting power relations (Marston \& Watts 2003, p. 145; Nutley et al. 2009, p. 20).

The reliability of evidence is also important, and it must be emphasised that no evidence is completely infallible (Hammersley 2005, p. 88). It is necessary to recognise that the process of researching and evaluating, similar to any other human endeavour, inevitably and unavoidably relies on interpretation and judgement (Hammersley 2005, p. 89; McConnell 2010, p. 129; Banks 2009, p. 17; Marsh \& McConnell 2010, p. 573). Producing research can only be guided by methodological principles, but never governed (Hammersley 2005, p. 89). Research guidelines can never entirely remove the element of judgement that is always involved (Hammersley 2005, p. 92; Banks 2009, p. 17). Furthermore, it can be argued that because of the fallible nature of evidence, it should be reasonable to expect policymakers to critically assess and analyse research claims, drawing on their professional experiences and knowledge in doing so (Hammersley 2005, p. 88). It has been said that judgement should not be thought of as an inevitable source of bias any more than methodological rigor should be trusted as a source of neutrality or validity (Hammersley 2005, p. 92).

The question of who produces the evidence or how it becomes known and discussed is also critical for understanding the reliability of evidence (Nutley et al. 2009, p. 18). In many policy areas, networks of organisations and interest groups outside of government have emerged that have a significant role in shaping policy (Nutley et al. 2009, p. 19; Nutley 2003, p. 11). These include charitable agencies, campaign organisations, lobby groups, and think tanks, who have an active research function (Nutley et al. 2009, p. 19). While it has been argued that these groups represent a democratising of the policy process in that it is more participatory and there is greater diversity of perspectives, the values and assumption embedded in their research and analyses must not be taken for granted (Nutley et al. 2009, pp. 19, 20). Many of these interest groups involved in such research advocacy:

may devote considerable resources to exploiting and developing the evidence base, and they can be seen to deploy a number of strategies to increase the impact that their evidence informed advocacy may have on policy (Nutley et al. 2009, p. 19).

Essentially, in many cases, the research conducted by these groups is not in the interest of knowledge, but as a side effect of advocacy' (Weiss 1986, p. 280). 
The last major issue with evidence-based policymaking is not only multiple evidence bases, but also the selective framing and partisan use of evidence (McConnell 2010, p. 129). That is, the way evidence can be promoted or ignored in the policymaking process, depending on political objectives (Pawson 2006, p. 5; Head 2008, p. 5; McConnell 2010, p. 129; Sanderson 2002, p. 5; Nutley et al. 2009 , p. 10). While still seeking to legitimise their policies by highlighting the use of evidence, policymakers can cherry pick the evidence that best supports their already established opinions and platforms (Sanderson 2002, p. 5; McConnell 2010 , p. 129; Head 2008, p. 5). In other words, evidence will only be used when it aligns with ideological values, suits pre-existing politically motivated priorities, or does not challenge the status quo, hence the ironic term 'policybased evidence' (Banks 2009, p. 8; Sanderson 2002, p. 5; Nutley et al. 2009, p. 8). Evidence is never simply "'out there", unproblematised and just waiting to inform rational policy choices' (Maddison 2012, p. 273). Rather, policymakers who may already be committed to particular policy outcomes can influence the extent to which some evidence is used to inform decisions and other evidence is ignored or dismissed as irrelevant (Maddison 2012, p. 273; Head 2008, p. 5). Furthermore, the selective framing of evidence also has significant implications for research and science, in that politics now has influence over what research gets endorsed or supported, and how it is conducted (Nutley et al. 2009, p. 8). This is extremely problematic for those who consider the separation of research and policy as essential to holding governments accountable in the way that independent research can 'speak truth to power' (Nutley et al. 2009, p. 8).

Indigenous policy is a pertinent example of the complexities of evidencebased policymaking and the embedded power dynamics. The domain of Indigenous policy in Australia has been described as 'turbulent', that is, highly contested, 'ideologically fraught', marked by significant conflict in values, and where evidence-based arguments often become highly politicised (Head 2010, p. 81; Maddison 2012, pp. 270, 273). This is particularly evident in terms of what exactly counts as evidence (Maddison 2012, pp. 270, 271). It has been argued that ideological notions of race and racial superiority have been influential factors in deciding what counts as evidence to inform Indigenous policy (Maddison 2012, p. 271). It is acknowledged that some non-Indigenous researchers are much better able to influence the policy debate, while Indigenous knowledge is often ignored or dismissed (Maddison 2012, p. 271; Anderson 2003 , p. 228). Moreover, the focus on technical and academic research, which is largely not informed by Indigenous perspectives and yet tends to carry the most weight with governments, ignores other important sources of evidence (Maddison 2012, p. 271). Indigenous voices and ways of knowing, as well as evidence gathered through public inquiries and consultation that captures their experiences and knowledge, are often crowded out in the policy field by more mainstream evidence that support government platforms (Maddison 2012, 
p. 271; Anderson 2003, p. 228). However, as Ian Anderson (2003) argues, despite the interpretive challenges these forms of knowledge present, without engaging them within policymaking, it is 'inconceivable that there should be any other way of enabling Aboriginal participation in ... policy development' (p. 228).

It is not only ideology that influences the evidence base used in Indigenous policymaking, but also the institutional mechanisms that allow some perspectives to be heard over others (Maddison 2012, p. 272). Indigenous policymaking in Australia essentially takes place in a context of severe structural inequality where 'governments hold almost all the cards' (Maddison 2012, p. 272). Indigenous peoples are only involved in policymaking as a matter of choice by governments, rather than as a requirement (Chesterman 2008, p. 421). Moreover, their limited 'institutional capacity' means their voices can be less heard by policymakers (Maddison 2012, p. 272). This is exemplified in the dismantling of the Aboriginal and Torres Strait Islander Commission (ATSIC) by the Howard Government in 2005 and their refusal to establish another national entity with policymaking power in its place (Chesterman 2008, p. 419). While there are now independent entities, there is no longer a representative Indigenous body within government empowered to engage in the policymaking processes concerned with Indigenous affairs in the capacity that ATSIC did (Chesterman 2008 , p. 421). While there were certainly problems with ATSIC, there are now nevertheless implications for the ability of Indigenous peoples to participate in and influence the evidence-based policymaking process in Australia.

The use and framing of knowledge and evidence is also apparent within Indigenous policymaking, exemplified by the Northern Territory Intervention of 2007 (Maddison 2012, p. 269). The Intervention was a legislated response to allegations of child abuse within Aboriginal communities in the Northern Territory (AGDSS 2012). It included increased law enforcement, including the deployment of Australian Defence Force troops, new restrictions on pornography and alcohol, as well as changes to the provision of welfare, among other things (AGDSS 2013; Chesterman 2008, p. 419). According to the then Prime Minister John Howard and then Indigenous Affairs Minister Mal Brough, the response was heavily based on, and informed by, the evidence presented in the Little Children are Sacred report commissioned by the Northern Territory Government (Maddison 2012, p. 269). However, Pat Anderson (2011), co-author of the report, has criticised the government for not acknowledging or respecting the evidence that was put forward, adopting a strategy of 'imposed solutions and paternalism' rather than one 'based on empowerment and inclusion' which the evidence had suggested (p. 27). Anderson remarks in relation to the government's response: 
So, where was the evidence-base for this radical re-shaping of policy, for this return to a paternalistic approach to problem-solving? Simply: it was absent ... There was no attempt to address the fact that the vast majority of the evidence pointed in exactly the opposite direction to where the policy was going ... (p. 27).

Anderson also notes that the decision-making process for the Intervention took place largely behind closed doors (p. 28). However, it can nevertheless be argued that although there was no contestation about the fact that action was necessary, the evidence was likely used simply to advance prevailing political objectives (Anderson 2011, pp. 28, 29). As Anderson notes, some have argued the Intervention was a political exercise to gain advantage in an election year while others have seen it as an opportunity to advance the government's ideological agenda of undermining Indigenous rights, particularly land rights (p. 28). Others argue that even if the motives were genuine, it was marked by ignorance, prejudice and certainly not based on the evidence (Anderson 2011, p. 28). Moreover, it was not the rational kind of policy process heralded by the evidence-based agenda (Anderson 2011, p. 29). It can therefore be seen that despite access to evidence and the rhetoric of evidence as the basis for policy, policymaking is certainly not immune from greater ideological influences (Maddison 2012, p. 271).

This paper has considered the advantages of evidence-based policymaking as well as identified the challenges inherent in the concept. Certainly the idea that policymaking should not be based on evidence is something that not even the harshest critics of evidence-based policymaking would promote, and it should not be concluded that scientific research is not valuable or does not have anything important to contribute (Nutley et al. 2009, p. 7; Parsons 2002, p. 57). However, the political nature of policymaking necessarily makes the concept of evidence-based policymaking incredibly complex. It must also be critically questioned what counts as evidence in the first place, and such evidence needs to be placed in a wider context of other important forms of knowledge (Head 2008, p. 4). The matters of whose evidence is informing policy decisions, the potential fallibility of such evidence, as well as the selective use of it to support political objectives must also be examined. Exemplified by Indigenous policymaking in Australia, it can be argued that the practice of evidence-based policymaking is not necessarily a guarantee of more robust, effective or successful policy (Maddison 2012, p. 271). Research evidence is clearly only one of the factors influencing policymaking and therefore, evidence-aware or evidence-informed may be more appropriate terms for the concept (Nutley et al. 2009, p. 7, Marston \& Watts 2003, p. 145; Cherney \& Head 2010, p. 509). 


\section{Bibliography}

Australian Government Department of Social Services (AGDSS). 'Northern Territory Emergency Response'. www.dss.gov.au/our-responsibilities/ indigenous-australians/programs-services/closing-the-gap/closing-the-gapengagement-and-partnership-with-indigenous-people/northern-territoryemergency-response (26 June 2012), accessed 7 April 2014.

Australian Government Department of Social Services (AGDSS). 'About the Response'. $\quad$ www.dss.gov.au/our-responsibilities/indigenous-australians/ programs-services/closing-the-gap-in-the-northern-territory/northernterritory-emergency-response-nter-redesign/about-the-response (1 May 2013), accessed 7 April 2014.

Australian Government Productivity Commission (AGPC). 'Strengthening Evidence-Based Policy in the Australian Federation 2009'. Roundtable Proceedings, Volume Two: Background Paper. Canberra, August 17-18.

Anderson, Ian. 'Evidence and Aboriginal Health Policy'. In Evidence-Based Health Policy: Problems and Possibilities. Eds. Lin, Vivian and Gibson, Brendan (Oxford: Oxford University Press, 2003) 224-236.

Anderson, Pat. 2011, 'Research for a Better Future'. Keynote Address to the Third Aboriginal Health Research Conference, Coalition for Research to Improve Aboriginal Health, Sydney, 5-6 May. www.lowitja.org.au/sites/default/files/ docs/Pat_Anderson-CRIAH-27_04_2011.pdf, accessed 16 April 2014.

Banks, Gary. 2009, Evidence-Based Policy Making: What is it? How do we get it? (ANU Public Lecture Series, Presented by ANZSOG, 4 February). Productivity Commission, Canberra.

Blair, Tony and Cunningham, Jack. 1999, Modernising Government. Prime Minister and Minister for the Cabinet Office. London, United Kingdom.

Cherney, Adrian and Head, Brian. 'Evidence-Based Policy and Practice: Key Challenges for Improvement'. Australian Journal of Social Issues 45:4 (2010) 509-526.

Chesterman, John. 'National Policy-Making in Indigenous Affairs: Blueprint for an Indigenous Review Council'. Australian Journal of Public Administration $67: 4$ (2008) 419-429.

Hammersley, Martyn. 'Is the Evidence-Based Practice Movement Doing More Good than Harm? Reflections on Iain Chalmers' Case for Research-Based Policy Making and Practice'. The Policy Press 1:1 (2005) 85-100. 
Head, Brian. 'Three Lenses of Evidence-Based Policy'. Australian Journal of Public Administration 67:1 (2008) 1-11.

Head, Brian. 'Reconsidering Evidence-Based Policy: Key Issues and Challenges'. Policy and Society 29:2 (May 2010) 77-94.

Jensen, Paul. 2013, What is Evidence-Based Policy? Policy Brief 4/13. Melbourne Institute of Applied Economic and Social Research.

Kavanagh, Anne, Daly, Jeanne, Melder, Angela and Jolley, Damien. "“Mind the Gap": Assessing the Quality of Evidence for Public Health Problems'. In Evidence-Based Health Policy: Problems and Possibilities. Eds. Lin, Vivian and Gibson, Brendan (Oxford: Oxford University Press, 2003) 70-79.

Lewis, Jenny. 'Evidence-Based Policy: A Technocratic Wish in a Political World'. In Evidence-Based Health Policy: Problems and Possibilities. Eds. Lin, Vivian and Gibson, Brendan (Oxford: Oxford University Press, 2003) 250-259.

Lin, Vivian and Gibson, Brendan. 'Introduction'. In Evidence-Based Health Policy: Problems and Possibilities. Eds. Lin, Vivian and Gibson, Brendan (Oxford: Oxford University Press, 2003) xvii-xxvi.

Maddison, Sarah. 'Evidence and Contestation in the Indigenous Policy Domain: Voice, Ideology and Institutional Inequality'. Australian Journal of Public Administration 71:3 (2012) 269-277.

Marsh, David and McConnell, Allan. 'Towards a Framework for Establishing Policy Success'. Public Administration 88:2 (2010) 564-583.

Marston, Greg and Watts, Rob. 'Tampering With the Evidence: A Critical Appraisal of Evidence-Based Policy-Making'. The Drawing Board: An Australian Review of Public Affairs 3:3 (March 2003) 143-163.

McConnell, Allan. Understanding Policy Success: Rethinking Public Policy (Basingstoke: Palgrave Macmillan, 2010).

Nutley, Sandra. 2003, 'Bridging the Policy/Research Divide: Reflections and Lessons from the UK'. Keynote paper presented to the National Institute of Governance Conference, Canberra, 23-24 April.

Nutley, Sandra, Walter, Isabel and Davies, Huw. 'Past, Present, and Possible Futures for Evidence-Based Policy'. In Evidence for Policy and DecisionMaking: A Practical Guide. Ed. Argyrous, George (Sydney: University of New South Wales Press Ltd, 2009) 1-23. 
Parsons, Wayne. 'From Muddling Through to Muddling Up - Evidence Based Policy Making and the Modernisation of the British Government'. Public Policy and Administration 17:3 (July 2002) 43-60.

Pawson, Ray. Evidence-Based Policy: A Realist Perspective (London, Sage Publications Ltd, 2006).

Sanderson, Ian. 'Evaluation, Policy Learning and Evidence-Based Policy Making'. Public Administration 80:1 (2002) 1-22.

Solesbury, William. 2001, Evidence Based Policy: Whence it Came and Where It's Going. Working Paper 1. ESRC UK Centre for Evidence Based Policy and Practice, University of London.

Stevens, Alex. 'Survival of the Ideas that Fit: An Evolutionary Analogy for the Use of Evidence in Policy'. Social Policy and Society 6:1 (January 2007) 25-35.

Stevens, Alex. 'Telling Policy Stories: An Ethnographic Study of the Use of Evidence in Policy-Making in the UK'. Journal of Social Policy 40:2 (April 2011) 237-255.

Taylor, Marilyn and Balloch, Susan. 'The Politics of Evaluation: An Overview'. In The Politics of Evaluation: Participation and Policy Implementation. Eds. Taylor, Marilyn and Balloch, Susan (Bristol: The Policy Press, 2005) 1-17.

Weiss, Carol. 'The Circuitry of Enlightenment: Diffusion of Social Science Research to Policymakers'. Science Communication 8:2 (December 1986) 271-281. 
This text is taken from The ANU Undergraduate Research Journal, Volume Six, 2014, edited by Jonathon Zapasnik and Alexandra Hogan, published 2015 by ANU eView, The Australian National University, Canberra, Australia. 